\title{
STABILITY INDICATING RP-HPLC METHOD FOR ESTIMATION OF REPAGLINIDE IN RABBIT PLASMA
}

\section{RAJA NAVAMANISUBRAMANIAN ${ }^{1}$, SABITHA PANCHAGIRI ${ }^{2}$, RAGHUNANDAN NERELLA ${ }^{1}$, CHAMUNDEESWARI DURAIPANDIAN $^{3}$, SHANMUGANATHAN SEETHARAMAN ${ }^{*}$}

${ }^{1}$ Balaji Institute of Pharmaceutical Sciences, Laknepally (V), Narsampet (M), Warangal (R), India, ${ }^{2}$ Department of Pharmaceutical Sciences, UCPSc., Kakatiya University, Warangal, India, ${ }^{3}$ Department of Pharmacognosy, ${ }^{4}$ Department of Pharmaceutics, Faculty of Pharmacy, Sri Ramachandra Institute of Higher Education and Research (Deemed to University), Porur, Chennai, India. Email: shanmugganathan@sriramachandra.edu.in

Received: 24 Sep 2018, Revised and Accepted: 05 Mar 2019

\section{ABSTRACT}

Objective: A simple, selective and sensitive reverse-phase high-performance liquid chromatography (RP-HPLC) method to estimate repaglinide (REP) in rabbit plasma using rabeprazole (RAB) as an internal standard was developed and validated for various qualifications.

Methods: The chromatographic separation was performed on $\mathrm{C}_{18}$ (2) analytical column $(5 \mu, 250 \times 4.6 \mathrm{~mm})$ using acetonitrile: $0.05 \%$ trifluoroacetic acid in water $(55: 45, \mathrm{v} / \mathrm{v})$ as mobile phase at the flow rate of $1 \mathrm{ml} / \mathrm{min}$. Validation of the analytical method was performed as per ICH guidelines.

Results: The retention times of REP and RAB were found at $\sim 4.3$ and 5.1 min respectively, with adequate system suitability parameters (theoretical plates $\geq 3619$, tailing factor $\leq 1.38$, resolution factor 2.37$)$. The method has linearity over a concentration range of 10 to $1000 \mathrm{ng} / \mathrm{ml}\left(\mathrm{r}^{2}=0.9987\right)$. The results of accuracy $(\geq 98.17 \%)$, intra-, inter-day precision $(\leq 2.9 \%)$, recovery $(101.21 \pm 2.09 \%)$ and process efficiency $(99.77 \pm 3.74 \%)$ found satisfactory with no matrix effect. The analyte in samples were found stable up to $6 \mathrm{~h}, 3$ freeze-thaw cycles and not more than 2 mo corresponding to bench-top, short and long term stability studies respectively.

Conclusion: The developed RP-HPLC method for estimation of REP in rabbit plasma was developed. The method was found to be rapid, costeffective and accurate to estimate the REP from the sample matrix. The method can be a most useful tool for in vivo study of REP in the rabbit.

Keywords: HPLC-UV, Repaglinide, Bioanalytical, Validation, Rabbit plasma

(C) 2019 The Authors. Published by Innovare Academic Sciences Pvt Ltd. This is an open access article under the CC BY license (http://creativecommons.org/licenses/by/4.0/) DOI: http://dx.doi.org/10.22159/ijap.2019v11i3.33675

\section{INTRODUCTION}

Repaglinide (REP) is a novel carbomoxyl methyl benzoic acid derivative, also known as 2-ethoxy-4-[2-[[3-methyl-1-[2(lpiperidinyl)-phenyl] butyl] amino]-2-oxoethyl]-benzoic acid (fig. 1) [1]. It is a novel short-acting secretagogue belongs to meglitinide class, used to regulate fasting as well as postprandial elevated blood glucose in patients under the treatment of type-II diabetes mellitus $[2,3]$. It was understood from the literature that, REP reduces the hyperglycemia by stimulating pancreas through depolarization of $\beta$ cells via $\mathrm{K}^{+}{ }_{\mathrm{ATP}}$ channel blockade at plasma membrane, thereby ensue $\mathrm{Ca}^{2+}+$ influx through voltage-dependent channels, that triggers the $\mathrm{Ca}^{2+}$ dependent exocytosis of insulin-containing granules [2-5].

To date, several analytical techniques have been reported to estimate REP from human plasma, involving competitive solid-phase enzyme immunoassay [6], high-performance liquid chromatography (HPLC) integrated with electrochemical [7], ultraviolet (UV) [8, 9], photodiode-array (PDA) [10], detectors. Gradient elution techniques for concurrent estimation of REP with other anti-diabetic agents from the biological matrix on HPLC using UV detection were reported [8, 9]. Furthermore, HPLC-tandem mass spectrometry (LC/MS/MS) methods were established to assess the REP from plasma and urine samples of human [10, 11], monkey [12], rat [13] and equine [14]. Though, Gandhimathi et al., Berecka et al., Joshi et $a l$ and Soni et al. were reported HPLC methods to estimate the REP alone or combined with other drugs from pharmaceutical formulations but were not applied for biological samples [15-18]. However, all the above methods reported for REP estimation from biological matrix need of expensive instruments for gradient elution and for eluate detection, restrict the application of them in common research laboratories equipped with limited resources.

The principle objective of the present study was to establish a simple, selective and precised reverse phase-HPLC (RP-HPLC) integrated with ultraviolet (UV) detection method to quantify REP in rabbit plasma using rabeprazole (RAB) as an internal standard (IS).
Further, an attempt was done to validate the developed analytical method for essential qualifications like selectivity, linearity, recovery, accuracy, precision and other suitable validation parameters.<smiles>CCOc1cc(CC(=O)NC(CC(C)C)c2ccccc2N2CCCCC2)ccc1C(=O)O</smiles>

Fig. 1: Chemical structure of REP

\section{MATERIALS AND METHODS}

\section{Chemicals and reagents}

REP and RAB pure drug samples were acquired from KP Labs, Hyderabad, India. HPLC grade acetonitrile (ACN) and methanol were supplied by Rankem, Hyderabad, India. Trifluoroacetic acid (TFA) was supplied by SDFCL, Mumbai, India. HPLC grade water was used during the entire procedure. Heparin-coated blood sampling tubes were purchased from CML biotech (P) Ltd., Kerala, India.

\section{Instrumentation and chromatographic condition}

The HPLC (Shimadzu, Kyoto, Japan) system consists of a binary pump (LC-20AD), equipped with UV/Visible detector (SPD-A20), a Rheodyne injector port (7725i) with $20 \mu \mathrm{l}$ loop volume and the data 
acquisition was done by LC-solutions software. Weighing of materials was done with $0.1 \mathrm{mg}$ precision balance (Denver Instruments, New York). Plasma samples processing was included vortex mixer, refrigerated centrifuge and deep freezer (Remi, India)

The chromatograms were developed on an analytical column C18 (2), $250 \times 4.6 \mathrm{~mm} ; 5 \mu$ particle size (Luna ${ }^{\circledR}$, Phenomenex) via isocratic elution by fixed composition of ACN:0.05\% TFA in water (55:45, v/v) mixture as mobile phase, pumped with constant flow rate $(1 \mathrm{ml} / \mathrm{min})$ and $285 \mathrm{~nm}$ was set as detection wavelength for entire study. The composition of eluent was admixed freshly for total volume required, passed through a membrane filter $(\# 0.45 \mu \mathrm{m})$ and degassed by ultrasonic bath sonication for $30 \mathrm{~min}$ precedent to each batch analysis.

\section{Standard solutions and quality control samples}

Individual primary stock solutions of REP and RAB $(1 \mathrm{mg} / \mathrm{ml})$ were prepared using methanol as solvent and kept at $-20^{\circ} \mathrm{C}$ temperature to avoid decomposition of analyte on storage. The primary stock solution of REP was diluted appropriately with mobile phase mixture to obtain working standards (WS) in concentrations of 0.1 , $0.25,0.5,1,2.5,5$ and $10 \mu \mathrm{g} / \mathrm{ml}$, similarly, a single WS solution of IS $(5 \mu \mathrm{g} / \mathrm{ml})$ was also prepared for entire study. The standards for calibration (CS) were made by spiking of individual rabbit plasma $(180 \mu \mathrm{l})$ with each WS solution of REP $(20 \mu \mathrm{l})$ to result in $(10,25,50$, $100,250,500$ and $1000 \mathrm{ng} / \mathrm{ml})$ plasma-drug mixture $(200 \mu \mathrm{l})$ prior to analysis was done. Quality control (QC) standards of REP at 4 different levels at lower limit of quantitation (LLOQ), low QC (LQC; 3*LLOQ), medium QC (MQC; $50 \%$ of upper LOQ) and high QC (HQC; $90 \%$ of upper LOQ) were independently made at concentration level of $10 \mathrm{ng} / \mathrm{ml}, 30 \mathrm{ng} / \mathrm{ml}, 500 \mathrm{ng} / \mathrm{ml}$ and $900 \mathrm{ng} / \mathrm{ml}$ respectively as like method described for CS.

\section{Extraction procedure}

Preparation of samples for injection to develop the chromatogram was done as per extraction procedure reported earlier by Yin et al. and Ma et al., with fewer modifications $[19,20]$. To $200 \mu \mathrm{l}$ rabbit plasma (blank/test/CS/QC) sample transferred in an eppendorf tube $(2 \mathrm{ml})$ quadruple volume $(800 \mathrm{ml})$ of ACN and $20 \mu \mathrm{l}$ WS solution of $\mathrm{RAB}(5 \mu \mathrm{g} / \mathrm{ml})$ was added as extraction reagent and IS respectively, capped and vortexed on a cyclomixture for $1 \mathrm{~min}$. The mixture resulted was subjected to refrigerated centrifuge at $5000 \mathrm{~g}$ for $15 \mathrm{~min}$ at $4^{\circ} \mathrm{C}$. The protein-free clear supernatant $(500 \mu \mathrm{l})$ was shifted into a fresh eppendorf tube $(1 \mathrm{ml})$ and evaporated to dryness in a vacuum concentrator. Reconstitution of the residue was done with mobile phase mixture $(100 \mu \mathrm{l})$, capped, vortexed for a min and centrifuged again at $5000 \mathrm{~g}$ for $15 \mathrm{~min}$ at refrigerated condition $\left(4^{\circ} \mathrm{C}\right)$. The particle-free clear supernatant $(20 \mu \mathrm{l})$ was allowed to inject into the HPLC column to develop chromatogram.

\section{Method validation}

The validation approach is essential to demonstrate the competency of an analytical method for its purpose intended. The validation of the analytical method was conducted for essential qualifications like selectivity, linearity, accuracy, precision, LLOQ, matrix effect, recovery, performance of the method and stability of analyte were studied in accordance with guidelines of International Conference on Harmonization (ICH) and Food and Drug Administration (FDA) guidelines for bioanalytical method validation [21,22].

\section{Selectivity}

The blank chromatograms of plasma sample $(n=3)$ were examined for probable interfering peaks at the detection time of REP and IS. In addition, chromatograms developed for rabbit plasma $(n=3)$ spiked with IS alone and chromatograms of plasma spiked with both REP and IS were carefully examined for peak deriving and for significant interfering of each on other [22].

\section{Linearity, range and lower limit of quantitation}

Linearity was measured through $\left(1 / \mathrm{x}^{2}\right)$ weighed linear regression equation (mean $\mathrm{r}^{2} ; \mathrm{n}=5$ ) of calibration graph plotted employing seven nonzero concentrations of REP (between range 10 to 1000 $\mathrm{ng} / \mathrm{ml}$ ) spiked in rabbit plasma samples verses corresponding peak area ratio of REP:IS measured. Acceptance of the calibration curve was done when it passes good coefficient of correlation $\left(r^{2} \geq 0.98\right)$ and/or estimated precision (percentage coefficient of variation (\%CV)) of CS fall within accepted limits (LLOQ: $\pm 20 \% \mathrm{w} / \mathrm{w}$ and for all other CS levels within $\pm 15 \% \mathrm{w} / \mathrm{w}$ of theoretical/nominal concentration). LLOQ was defined as the least concentration of analyte present in plasma sample that could be determined with minimum accuracy $(80 \%$ to $120 \% \mathrm{w} / \mathrm{w})$ and precision $(\% \mathrm{CV})$ not more than (NMT) $20 \% \mathrm{w} / \mathrm{w}[10,22]$.

\section{Accuracy and precision}

Accuracy (percentage relative error (\%RE)) is the measure to which estimated value conforms to the theoretical/nominal amount of analyte exists in the sample matrix, was studied in 5 replicates of 4 QC levels (LLOQ: 10, LQC: 30, MQC: 500 and HQC: $900 \mathrm{ng} / \mathrm{ml}$ ) estimated against freshly constructed calibration curve (10 to 1000 $\mu \mathrm{g} / \mathrm{ml})$. The assay of QC levels was repeated in 3 separate runs within a day and in 3 distinct days to determine intra-and inter-day precision $(\% \mathrm{CV})$ respectively. The acceptance limit for accuracy as well as precision was set as NMT $\pm 20 \% \mathrm{w} / \mathrm{w}$ for LLOQ and for all other QC level is NMT $\pm 15 \% \mathrm{w} / \mathrm{w}[22,25]$.

\section{Matrix effect (ME), extraction efficiency (EE) and process efficiency (PE)}

All these parameters were studied using 3 sets of samples at 3 individual QC levels (LQC: 30, MQC: 500 and HQC: $900 \mathrm{ng} / \mathrm{ml}$ ) along with IS in triplicate. Set 1: QC levels prepared in methanol, set 2: QC levels spiked into liquid extracts of blank plasma and set 3: samples extracted from plasma spiked with QC levels. The ME was determined by relating the assay of set 2 with set 1 ; recovery was estimated by comparing set 3 with set 2 and PE was calculated by comparing set 3 with set 1 . The EE was assessed from percentage recovery should be consistent rather than high value $[22,23]$.

\section{Stability studies}

Stability of an analyte in the sample matrix is dependent on storage conditions and duration, chemical properties of an analyte and the matrix. Stability of REP in sample matrix was determined in triplicate, by assay of QC samples at 2 levels (LQC: 30 and HQC: $900 \mathrm{ng} / \mathrm{ml}$ ) in all types of study. In bench-top stability study, the integrity of the REP and IS in wet state (blood and reconstituted sample) and dry state (extracted residue for reconstitution) samples were studied separately up to the average working period $(6 \mathrm{~h})$. Stress-induced stability was assessed by subjecting the QC (plasma) samples for 3 freeze-thawing $\left(-25^{\circ} \mathrm{C}\right.$ to $\left.4^{\circ} \mathrm{C}\right)$ in a frequency of 1 cycle per day, in that the samples were kept at least $18-20 \mathrm{~h}$ in frozen state and 4-6 h thawing state in each cycle. The frozen QC samples were slowly thawed to room temperature at the end of each cycle and assayed to study the precision. In assessing long term stability, assay of the stored QC samples $\left(-20^{\circ} \mathrm{C}\right)$ was done after thawing the samples to room temperature in order to determine the precision by end of $0,1^{\text {st }}, 2^{\text {nd }}$ and $3^{\text {rd }}$ months. In all type of stability studies 0 time $/ 0$ cycle samples were kept as control and to which other samples were compared to assess the significance of difference by one way ANOVA [22-27].

\section{Statistical analysis}

All the results of assay, validation parameters and in vivo animal pharmacokinetic parameters were expressed in mean $\pm \mathrm{SD}, \% \mathrm{CV}$ and $\%$ RE. Statistical significance of variations was studied by one way ANOVA done by data analysis tool pack, Microsoft excel@ (2007).

\section{RESULTS}

\section{Optimization of chromatographic condition}

The chromatographic separation and elution of analyte was done by mobile phase consisting of ACN:0.05\% TFA in water $(55: 45, \mathrm{v} / \mathrm{v})$ in reverse phase analytical column $(250 \times 4.6 \mathrm{~mm} ; 5 \mu$ particle size $)$. The retention times $\left(\mathrm{R}_{\mathrm{t}} \mathrm{s}\right)$ of REP and IS were found as $\sim 4.3$ and $5.1 \mathrm{~min}$ respectively. The system suitability parameters of the method were calculated as follows: theoretical plates for REP and IS were found as 4764 and 3619 respectively. Tailing factor was found as 1.16 and 1.38 for REP and IS respectively and the resolution between two drugs was found as 2.37 . 

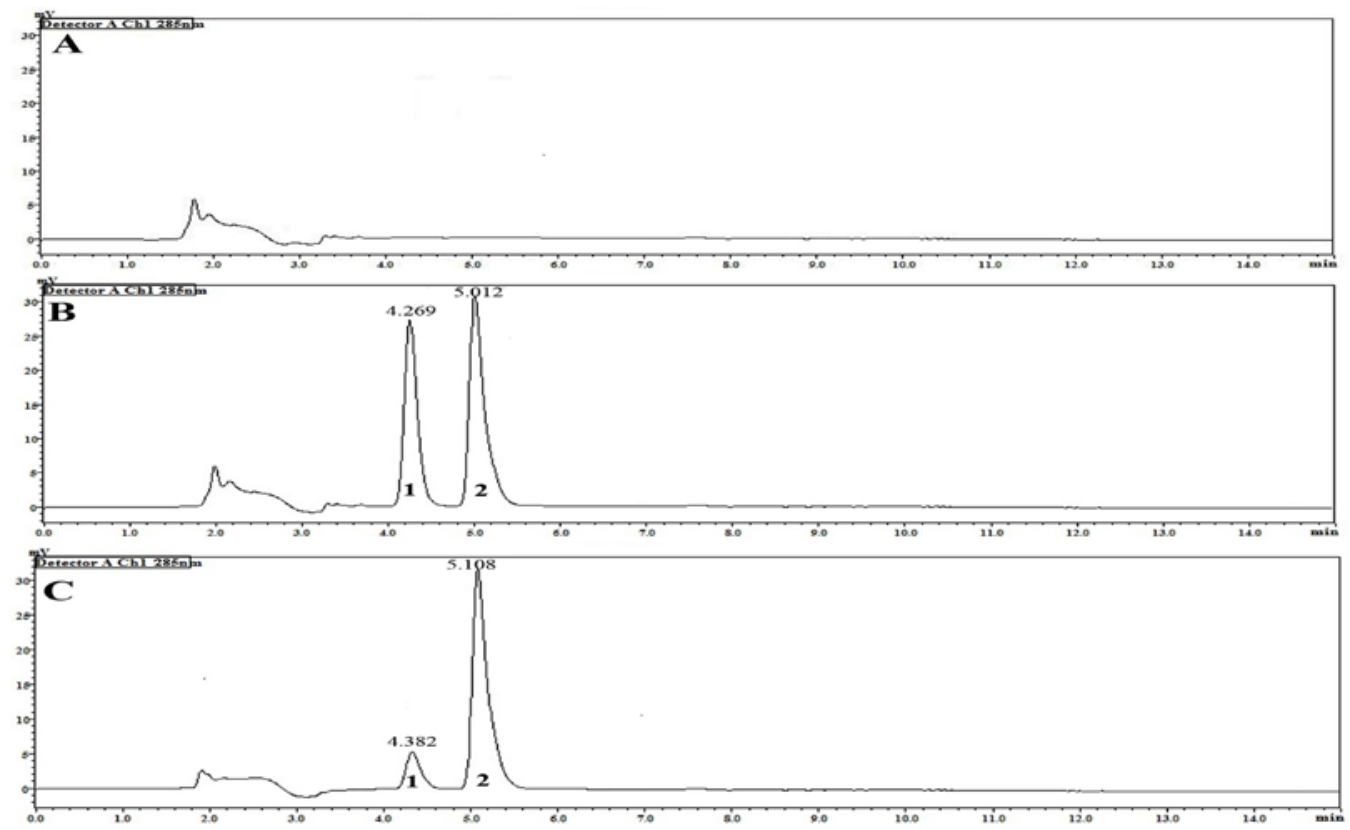

Fig. 2: Chromatograms of (A) blank plasma, (B) rabbit plasma spiked with $500 \mathrm{ng} / \mathrm{ml}$ concentration of REP and IS, (C) Plasma sample collected after $1 \mathrm{~h}$ following $4 \mathrm{mg}$ oral dosing of REP and spiked with IS

\section{Method validation}

\section{Selectivity}

The chromatogram of blank rabbit plasma sample (fig. 2. A) was compared with the chromatogram developed for rabbit plasma spiked with REP and IS (fig. 2. B). Further, the chromatogram of rabbit plasma sample collected at $1 \mathrm{~h}$ after $4 \mathrm{mg}$ oral dosing of REP with spiked IS was illustrated in fig. 2. C.

\section{Linearity, range and lower limit of quantitation}

The linear regression equation of calibration curve plotted was resulted as $Y=1.415 \mathrm{X}+0.0022$ with $\mathrm{r}^{2}$ value of 0.9987 and the linearity was found as high in between concentration range of 10 to
$1000 \mathrm{ng} / \mathrm{ml}$. The LOD and LOQ value calculated from the regression equation of the calibration curve was found as $1.73 \mathrm{ng} / \mathrm{ml}$ and 5.23 $\mathrm{ng} / \mathrm{ml}$ respectively. The practical LLOQ of REP in rabbit plasma sample was accepted as $10 \mathrm{ng} / \mathrm{ml}$.

\section{Accuracy and precision}

The accuracy and precision were expressed as \%RE and \%CV (table 1). The assay results studied for accuracy were varied between $98.17 \pm 2.71 \% \mathrm{w} / \mathrm{w}$ to $101.39 \pm 2.35 \% \mathrm{w} / \mathrm{w}$, with $\% \mathrm{RE}$ was ranged from $-1.82 \% \mathrm{w} / \mathrm{w}$ to $1.39 \% \mathrm{w} / \mathrm{w}$. The result of intra-day precision $(\% \mathrm{CV})$ was found between $0.65 \% \mathrm{w} / \mathrm{w}$ to $2.9 \% \mathrm{w} / \mathrm{w}$ and the inter-day precision was found in the range of $0.49 \% \mathrm{w} / \mathrm{w}$ to $2.76 \% \mathrm{w} / \mathrm{w}$.

Table 1: Results of accuracy and precision study $(n=5)$

\begin{tabular}{|c|c|c|c|c|c|c|}
\hline Conc. spiked (ng/ml) & Assay (\%w/w) & SD (\%w/w) & RE (\%w/w) & Conc. Found (ng/ml) & SD (ng/ml) & $\mathrm{CV}(\% \mathrm{w} / \mathrm{w})$ \\
\hline \multicolumn{7}{|l|}{ Intra Day } \\
\hline 10 & 101.02 & 2.93 & 1.02 & 10.1 & 0.29 & 2.9 \\
\hline 30 & 100.53 & 0.65 & 0.53 & 30.16 & 0.19 & 0.65 \\
\hline 500 & 99.72 & 2.19 & -0.28 & 498.6 & 10.96 & 2.19 \\
\hline 900 & 98.73 & 2.2 & -1.28 & 888.53 & 19.84 & 2.23 \\
\hline \multicolumn{7}{|l|}{ Inter Day } \\
\hline 10 & 101.39 & 2.35 & 1.39 & 10.14 & 0.24 & 2.32 \\
\hline 30 & 100.68 & 0.49 & 0.68 & 30.2 & 0.15 & 0.49 \\
\hline 500 & 98.17 & 2.71 & -1.82 & 490.88 & 13.56 & 2.76 \\
\hline 900 & 99.73 & 1.39 & -0.27 & 897.61 & 12.54 & 1.39 \\
\hline
\end{tabular}

Matrix effect (ME), extraction efficiency (EE) and process efficiency (PE)

The results of ME, EE and PE were determined by relating the assay of paired samples as described in the methods, was shown in table 2.
All these three parameters were studied at QC levels 30, 500 and $900 \mathrm{ng} / \mathrm{ml}$ in triplicates and the mean results determined for ME was $98.61 \pm 3.95$, EE was $101.21 \pm 2.09$ and PE was $99.77 \pm 3.74 \%$ $\mathrm{w} / \mathrm{w}$.

Table 2: Results of matrix effect, extraction efficiency and process efficiency

\begin{tabular}{|c|c|c|c|c|c|c|}
\hline \multirow[t]{2}{*}{ Drug conc. (ng/ml) } & \multicolumn{3}{|c|}{ Assay of sample* } & \multirow[t]{2}{*}{$\mathbf{M E}^{*}$} & \multirow[t]{2}{*}{$\mathbf{E E}^{*}$} & \multirow[t]{2}{*}{$\mathbf{P E}^{*}$} \\
\hline & Methanol & Unextracted & Extracted & & & \\
\hline 30 & $101.46 \pm 3.24$ & $99.26 \pm 1.53$ & $101.87 \pm 4.03$ & $97.89 \pm 3.01$ & $102.61 \pm 2.43$ & $100.44 \pm 4.06$ \\
\hline 50 & $99.67 \pm 5.16$ & $98.53 \pm 2.14$ & $99.73 \pm 1.92$ & $99.1 \pm 6.99$ & $101.24 \pm 2.15$ & $100.24 \pm 5.47$ \\
\hline 900 & $100.93 \pm 2.49$ & $99.74 \pm 2.48$ & $99.52 \pm 2.06$ & $98.84 \pm 2.13$ & $99.76 \pm 0.72$ & $98.63 \pm 2.52$ \\
\hline Mean** & 100.68 & 99.17 & 100.37 & 98.61 & 101.21 & 99.77 \\
\hline$\% \mathrm{RSD}^{* *}$ & 3.39 & 1.88 & 2.7 & 3.95 & 2.09 & 3.74 \\
\hline
\end{tabular}

*All the results represented as mean \pm SD $(n=3) ;{ }^{* *}$ All the results represented as mean \pm SD $(n=9)$ 


\section{Stability studies}

The bench-top stability study for the whole blood sample, dried and reconstituted samples after extraction was performed at $2 \mathrm{QC}$ levels in triplicates and the results were shown in table 3 . The results of stress-induced (freeze-thaw) and long term stability study (storing at $-20^{\circ} \mathrm{C}$ ) were reported in table 4 .

Table 3: Results of bench top stability study after $6 h(n=3)$

\begin{tabular}{lllr}
\hline QC Level & Conc. $(\mathbf{n g} / \mathbf{m l})$ & \%Accuracy & \%RSD \\
\hline blood & & & p-value \\
LQC & 30 & 101.74 & 5.85 \\
HQC & 900 & 99.85 & 4.43 \\
Reconstututed & 30 & 102.6 & 0.92 \\
LQC & 900 & 103.73 & 2.14 \\
HQC & & & 4.48 \\
Dry state & 30 & 100.2 & 0.17 \\
LQC & 900 & 99.62 & 0.56 \\
HQC & & & 0.85 \\
\hline
\end{tabular}

Table 4: Results of short term and long term stability study (n=3)

\begin{tabular}{|c|c|c|c|c|c|c|c|}
\hline \multicolumn{5}{|c|}{ Short term (Stress induced) stability } & \multicolumn{3}{|c|}{ Long term stability } \\
\hline QC Level & Conc. (ng/ml) & \%Accuracy & $\% \mathrm{CV}$ & p-value & \%Accuracy & $\% \mathrm{CV}$ & p-value \\
\hline Cycle 0 & & & & & O Mo & & \\
\hline LQC & 30 & 99.89 & 3.66 & - & 101.02 & 4.57 & - \\
\hline HQC & 900 & 100.37 & 1.75 & - & 100.91 & 2.75 & - \\
\hline Cycle 1 & & & & & 1 Mo & & \\
\hline LQC & 30 & 99.31 & 10.94 & 0.93 & 98.76 & 5.66 & 0.62 \\
\hline HQC & 900 & 95.53 & 8.91 & 0.41 & 99.79 & 3.03 & 0.66 \\
\hline Cycle 2 & & & & & 2 Mo & & \\
\hline LQC & 30 & 98.99 & 9.22 & 0.88 & 97.72 & 6.29 & 0.49 \\
\hline HQC & 900 & 98.2 & 7.05 & 0.63 & 95.45 & 5.53 & 0.19 \\
\hline Cycle 3 & & & & & 3 Mo & & \\
\hline LQC & 30 & 99.81 & 9.74 & 0.99 & 72.43 & 15.5 & 0.015 \\
\hline $\mathrm{HQC}$ & 900 & 98.06 & 10.93 & 0.73 & 69.64 & 17.24 & 0.012 \\
\hline
\end{tabular}

\section{DISCUSSION}

The chromatographic condition was optimized for bio-analysis of REP in rabbit plasma using RAB as IS on RP-HPLC consisting with UV detection. In this process, several compositions between ACN and TFA $(0.05 \% \mathrm{v} / \mathrm{v}$ in water) were tried as eluent to develop the chromatogram. Increased proportion of ACN in the mobile phase resulted in faster elution but the peaks of REP and IS were not completely separated. Reduction of ACN proportion in the mobile phase resulted tailing of peaks and it was found that mixture of ACN: $0.05 \%$ TFA in water $(55: 45, v / v)$ as optimum mobile phase composition by which the REP peak clearly resolved from IS peak and solvent fronts. In order to develop a liquid-liquid extraction method, various solvents (ACN, Methanol, Dichloromethane and ethyl acetate) were used for extraction of REP and IS from plasma samples, among that ACN found to be most efficient than all others. This method was simple and efficient in the extraction of analyte and chromatogram developing when compared to earlier reported methods by Venkatesh et al. and Ruzilawati et al. $[9,10]$. The system suitability parameters: theoretical plates $(>3000)$, Tailing factor $(<2)$ and resolution $(>2)$ for the developed HPLC method were satisfactory to meet the ICH guidelines [21].

The chromatogram of blank rabbit plasma sample was compared with the chromatogram developed for rabbit plasma spiked with REP and IS. No significant endogenous noise peaks around the $R_{t} s$ of REP and IS were found in chromatogram of blank plasma sample, justifies the selectivity of this analytical method. The calibration curve plotted using plasma concentration of REP $(X)$ versus mean peak area ratio of REP:IS of triplicates (Y) has high linear $\left(r^{2}=0.9987\right)$ with acceptable variability $(\leq 9.8 \%)$ in the selected concentration range indicates the sensitivity of the method as good. All the results of accuracy (\%RE) and Precision (\%CV) were found less than $\pm 1.82 \% \mathrm{w} / \mathrm{w}$ and $\pm 2.9 \% \mathrm{w} / \mathrm{w}$ respectively were complied with the official guidelines (\%RE and \%CV NMT $\pm 20 \% \mathrm{w} / \mathrm{w}$ for LLOQ and for other QC levels NMT $\pm 15 \% \mathrm{w} / \mathrm{w}$ ) confirms the method's accuracy and precision in estimation of analyte. The recovery of REP from plasma samples done by liquid extraction using ACN, shown better and consistent EE (99.76 to $102.61 \% \mathrm{w} / \mathrm{w}$ ) than earlier reported by Venkatesh et al. (92.37 to $106.50 \% \mathrm{w} / \mathrm{w})$ [8].

The bench-top stability was studied to find the influence of the maximum processing time on the integrity of analyte in the matrix. The REP is proved to be stable in the wet state as well as dry state samples during an average bench-top working period (6 h). Also, the chemical stability of REP in plasma was confirmed at the end of 3 stress cycles applied $(p \geq 0.73)$ and significant stability of analyte was retained in the plasma up to 2 mo $(\mathrm{p} \geq 0.19)$ during storage at $-20^{\circ} \mathrm{C}$, beyond that the integrity of analyte in the sample matrix was insignificant $(\mathrm{p} \leq 0.015)$.

\section{CONCLUSION}

A simple and selective RP-HPLC-UV method to estimate REP from rabbit plasma using RAB as an IS was developed and validated for various qualifications per ICH and FDA guidelines. The method is selective to estimate REP from the sample matrix, has good linearity, accuracy, precision and stability over the therapeutic range. The liquid extraction procedure used in this method was simple, reproducible with good extraction efficiency and process efficiency. The method could be applied to estimate the plasma concentration of REP after the suitable route of administration in New Zealand white rabbit to study the in vivo pharmacokinetics of REP from the dosage forms.

\section{ACKNOWLEDGMENT}

The authors are thankful to Balaji Institute of Pharmaceutical Sciences, Narsampet, Warangal and CEFT, Sri Ramachandra Institute of Higher Education and Research (Deemed to University), Chennai for the instrumental support to this study.

\section{AUTHORS CONTRIBUTIONS}

All the authors have equal contribution in this research work.

\section{CONFLICT OF INTERESTS}

The authors declared no conflict of interest 


\section{REFERENCES}

1. Marbury TM, Ruckle JL, Hatorp V, Andersen MP, Nielsen KK, Huang WC, et al. Pharmacokinetic of repaglinide in subjects with renal impairment. Clin Pharmacol Ther 2000;67:7-15.

2. Scott LJ. Repaglinide. Drugs 2012;72:249-72.

3. Kassem AA, El-Alim SHA, Basha M, Salama A. Phospholipid complex enriched micelles: a novel drug delivery approach for promoting the antidiabetic effect of repaglinide. J Pharm Sci 2017;99:75-84.

4. Stephan D, Winkler M, Kuhner P, Russ U, Quast U. Selectivity of repaglinide and glibenclamide for the pancreatic over the cardiovascular $\mathrm{K}_{\text {ATP }}$ channels. Diabetologia 2006;49:2039-48.

5. Jirovsky D, Bartosova Z, Skopalova J, Maier V. Electrochemical characterization of repaglinide and its determination in human plasma using liquid chromatography with dual-channel coulometric detection. J Chrom B 2010;878:3243-8.

6. Hatorp V, Huang WC, Strange P. Repaglinide pharmacokinetics in healthy young adult and elderly subjects. Clin Ther 1999;21:702-10.

7. Greischel A, Beschke K, Rapp H, Roth W. Quantitation of the new hypoglycaemic agent AG-EE388ZW in human plasma by automated high-performance liquid chromatography with electrochemical detection. J Chrom B 1991;568:246-52.

8. Yao J, Shi YQ, Li ZR, Jin SH. Development of a RP-HPLC method for screening potentially counterfeit anti-diabetic drugs. J Chrom B 2007;853:254-9.

9. Venkatesh P, Harisudhan T, Choudhury H, Mullangi R, Srinivas NR. Simultaneous estimation of six anti-diabetic drugs glibenclamide, gliclazide, glipizide, pioglitazone, repaglinide and rosiglitazone: development of a novel HPLC method for use in the analysis of pharmaceutical formulations and its application to human plasma assay. Biomed Chrom 2006;20:1043-8.

10. Ruzilawati AB, Abd Wahab MS, Imran A, Ismail Z, Gan SH. Method development and validation of repaglinide in human plasma by HPLC and its application in pharmacokinetic studies. J Pharm Biomed Anal 2007;43:1831-5.

11. Zhang J, Gao F, Guan X, Sun Y, Gu J, Fawcett JP. Determination of repaglinide in human plasma by high-performance liquid chromatography-tandem mass spectrometry. Acta Pharm Sin B 2011;1:40-5.

12. Wang M, Miksa IR. Multi-component plasma quantitation of antihyperglycemic pharmaceutical compounds using liquid chromatography-tandem mass spectrometry. J Chrom B 2007;856:318-27.

13. Sharma K, Pawar G, Yadam S, Giri S, Rajagopal S, Mullangi R. LC-MS/MS-ESI method for simultaneous quantitation of metformin and repaglinidie in rat plasma and its application to pharmacokinetic study in rats. Biomed Chrom 2013;27:356-64.

14. Ho EN, Yiu KC, Wan TS, Stewart BD, Watkins KL. Detection of antidiabetics in equine plasma and urine by liquid chromatographytandem mass spectrometry. J Chrom B 2004;811:65-73.
15. Gandhimathi M, Ravi TK, Renu SK. Determination of repaglinide in pharmaceutical formulations by HPLC with UV detection. Anal Sci 2003;19:1675-7.

16. Berecka A, Gumieniczek A, Hopkala H. Development and validation of a new high-performance liquid chromatography method for the determination of gliclazide and repaglinide in pharmaceutical formulations. J AOAC Int 2006;89:319-25.

17. Joshi SS, Nahire RR, Shastri NR, Surendranath KV, Satish J. Validated stability-indicating RP-HPLC UV method for simultaneous determination of metformin and repaglinide. Acta Chrom 2012;24:419-43.

18. Soni LK, Narsinghani T, Jain M. Development and validation of RP-HPLC method for simultaneous estimation of metformin hydrochloride and repaglinide in tablet dosage form. J Liq Chromatogr Relat Technol 2012;35:385-92.

19. Yin K, Meng X, Dong P, Ding T, Shen L, Zhang L, et al. A simple, rapid, economical, and practical method for the determination of efavirenz in plasma of Chinese AIDS patients by reversephase high-performance liquid chromatography with ultraviolet detector. BioSci Trends 2014;8:227-34.

20. Ma Z, Shayeganpour A, Brocks DR, Lavasanifar A, Samuel J. Highperformance liquid chromatography analysis of curcumin in rat plasma: application to the pharmacokinetics of polymeric micellar formulation of curcumin. Biomed Chrom 2007;21:546-52.

21. ICH Harmonised Tripartite Guideline, Validation of Analytical Procedures: Text and Methodology Q2 (R1). International Conference on Harmonisation of Technical Requirements for Registration of Pharmaceuticals for Human Use. Geneva; 2005. p. 1-13.

22. Guidance for industry: bioanalytical method validation, U. S. Department of health and human services, Food and Drug administration, Centre for Drug Evaluation and Research (CDER) Centre for Veterinary Medicine (CVM); 2018. p. 1-41.

23. Jimmerson LC, Zheng JH, Bushman LR, MacBrayne CE Anderson PL, Kiser JJ. Development and validation of a dried blood spot assay for the quantification of ribavirin using liquid chromatography coupled to mass spectrometry. J Chrom B 2014;944:18-24.

24. Bansal S, DeStefano A. Key elements of bioanalytical method validation for small molecules. AAPS J 2007;9:109-14.

25. Shanmugasundaram P, Bijithra C, Ragan G, Sankar A, Sumithra M. Analyitcal method development and validation of reversedphase high-performance liquid chromatography for the determination of modafinil in bulk and pharmaceutical dosage forms. Asian J Pharm Clin Res 2016;9:177-81.

26. Ashok P, Narenderan ST, Meyyanathan SN, Babu B, Vadivelan R. Development and validation of a RP-HPLC method for estimation of telmisartan in human plasma. Int J Appl Pharm 2019;11:237-40.

27. Mukti AA, Jannah F, Nurrochmad A, Lukitaningsih E. Development and validation method for quantitative determination of ciprofloxacin in human plasma and its application in bioequivalence test. Asian J Pharm Clin Res 2016;9:89-95. 